\title{
Trends in inpatient setting laminectomy for excision of herniated intervertebral disc: Population-based estimates from the US nationwide inpatient sample
}

\section{Citation}

Walcott, BrianP, BrianW Hanak, JamesR Caracci, Navid Redjal, BrianV Nahed, KristopherT Kahle, and Jean-ValeryC.E. Coumans. 2011. Trends in Inpatient Setting Laminectomy for Excision of Herniated Intervertebral Disc: Population-Based Estimates from the US Nationwide Inpatient Sample. Surg Neurol Int 2, no. 1: 7. doi:10.4103/2152-7806.76144.

\section{Published Version}

doi:10.4103/2152-7806.76144

\section{Permanent link}

http://nrs.harvard.edu/urn-3:HUL.InstRepos:35776706

\section{Terms of Use}

This article was downloaded from Harvard University's DASH repository, and is made available under the terms and conditions applicable to Other Posted Material, as set forth at http:// nrs.harvard.edu/urn-3:HUL.InstRepos:dash.current.terms-of-use\#LAA

\section{Share Your Story}

The Harvard community has made this article openly available.

Please share how this access benefits you. Submit a story. 


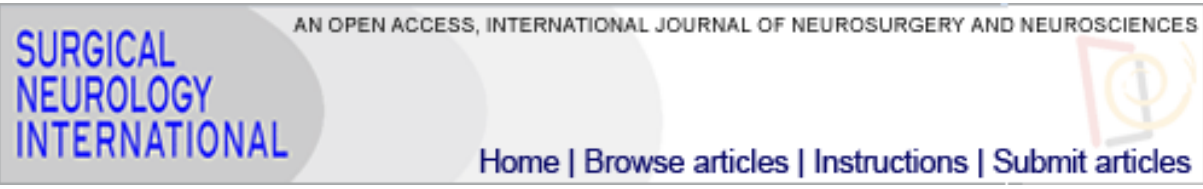

Surg Neurol Int. 2011; $2: 7$.

PMCID: PMC3031049

Published online 2011 Jan 24. doi: $10.4103 / 2152-7806.76144$

\title{
Trends in inpatient setting laminectomy for excision of herniated intervertebral disc: Population-based estimates from the US nationwide inpatient sample
}

\author{
Brian P. Walcott, Brian W. Hanak, James R. Caracci, Navid Redjal, Brian V. Nahed, Kristopher T. Kahle, and Jean- \\ Valery C.E. Coumans \\ Department of Neurological Surgery, Massachusetts General Hospital \& Harvard Medical School, Boston, MA 02114, USA \\ Brian P. Walcott: Walcott.brian@mgh.harvard.edu; Brian W. Hanak: Brian Hanak@hms.harvard.edu; James R. Caracci: \\ icaracci@partners.org; Navid Redjal: nredjal@partners.org; Brian V. Nahed: bnahed@partners.org; Kristopher T. Kahle: \\ kkahle@partners.org; Jean-Valery C.E. Coumans: jcoumans@partners.org \\ Corresponding author \\ Received 2010 Nov 7; Accepted 2010 Nov 30. \\ Copyright : @ 2011 Walcott BP \\ This is an open-access article distributed under the terms of the Creative Commons Attribution License, which permits unrestricted use, \\ distribution, and reproduction in any medium, provided the original author and source are credited.
}

\section{Abstract}

\section{Background:}

Herniated intervertebral discs can result in pain and neurological compromise. Treatment for this condition is categorized as surgical or non-surgical. We sought to identify trends in inpatient surgical management of herniated intervertebral discs using a national database.

\section{Methods:}

Patient discharges identified with a principal procedure relating to laminectomy for excision of herniated intervertebral disc were selected from the Nationwide Inpatient Sample (Healthcare Cost and Utilization Project - Agency for Healthcare Research and Quality, Rockville, MD), under the auspices of a data user agreement. These surgical patients did not undergo instrumented fusion. To account for the Nationwide Inpatient Sample weighting schema, design-adjusted analyses were used. The estimates of standard errors were calculated using SUDAAN software (Research Triangle International, NC, USA). This software is based on the International Classification of Diseases, $9^{\text {th }}$ Revision, Clinical Modification (ICD-9-CM); a uniform and standardized coding system.

\section{Results:}

Using International Classification of Disease $9^{\text {th }}$ Revision clinical modifier (ICD-9 CM) procedure code 80.51 , we were able to identify disc excision, in part or whole, by laminotomy or hemilaminectomy. The incidence of laminectomy for the excision of herniated intervertebral disc has decreased dramatically from 1993 where 266,152 cases were reported [CI $=22,342]$. In 2007, only 123,398 cases were identified [CI $=$ $12,438]$. The average length of stay in 1993 was 4 days [CI $=0.17$ ], and in 2007 it decreased to just 2 days $[\mathrm{CI}=0.17]$. Both these comparisons were significantly different at $\mathrm{P}<0.001$. The average inflation 
adjusted (2007 buying power) charge of the procedure in 1993 was 14,790.87 USD [CI $=916.85$ ]. This

value rose in 2007 to 24,639 USD [CI $=1,485.51]$. This difference was significant at $\mathrm{P}<0.001$.

\section{Conclusions:}

National estimates indicate that the incidence of inpatient laminectomy for the excision of herniated intervertebral disc has decreased significantly. This trend is multifactorial and is likely related to developments in outcomes research, the growing popularity of alternative procedures (intervertebral instrumented fusion), and transition to an ambulatory setting of surgical care.

Keywords: Clinical Trials as Topic, diskectomy, intervertebral disk, magnetic resonance imaging, spinal fusion, spondylosis

\section{INTRODUCTION}

We hypothesize that the incidence of laminectomy for intervertebral disc herniation in the inpatient setting has decreased over recent years. We also hypothesize that the length of inpatient stay for this procedure has decreased, although it has been associated with an increased cost. A complex clinical milieu influenced by ambulatory setting surgery, results of outcomes research, and alternative procedures may be responsible for trends observed.

\section{MATERIALS AND METHODS}

We studied the practice patterns relating to the surgical treatment of herniated lumbar intervertebral discs from 1993 to 2007, which we obtained from the Healthcare Cost and Utilization Project, Agency for Healthcare Research and Quality (AHRQ) Rockville, MD.[1] The Nationwide Inpatient Sample (NIS) is a hospital discharge database that represents approximately $20 \%$ of all inpatient admission to nonfederal hospitals in the US. The NIS contains discharge data on 100\% of discharges from 1993 to 2007. It is an expanding, stratified random sample of nonfederal hospitals now comprised of 1,044 hospitals in 40 states. Detailed information on the design of the NIS is available at http://www.hcup-us.ahrq.gov. The NIS includes greater than 100 clinical and non-clinical variables for each hospital stay. These include diagnoses, procedures, admission and discharge status, demographics, charges, and lengths of stay. Patients registered in the NIS from 1993 to 2007 were included in the analysis. Those undergoing surgical treatment for herniated intervertebral discs as the principal procedure were identified using International Classification of Disease $9^{\text {th }}$ Revision clinical modifier (ICD-9 CM) procedure code 80.51 . This identifies excision, in part or whole, of an intervertebral disc by laminotomy or hemilaminectomy, including decompression of the spinal nerve root at the same level. No accounting could be made for the degree of disc herniation, number of intervertebral levels involved, neurological impairment, traumatic disc herniation, level of surgery, or the timing of surgery.

While the ICD-9 CM code for laminectomy for excision of intervertebral disc in description captures all disc herniations treated by laminectomy in the entire spine, it likely reflects mainly lumbar disc herniations. The lumbar region is the most common location of intervertebral disc herniation. Furthermore, laminectomies are less commonly performed for the treatment of cervical intervertebral herniated discs. Therefore, analysis of this ICD-9 CM code inherently self-selects to describe mainly those trends that are found in the lumbar region.

In addition, other inpatient statistics thought to be related to herniated intervertebral disc disease, (such as spinal fusion procedures [Clinical Classifications Software for ICD-9-CM category 158]), were queried.

To account for the Nationwide Inpatient Sample weighting schema, design-adjusted analyses were used. The estimates of standard errors were calculated using SUDAAN software (Research Triangle 
International, NC, USA). A Z-test was then used to determine the significance of the yearly incidence changes over the study period.

Hospital charges for the two types of surgical procedures were calculated based on hospital accounting reports from the Centers for Medicare and Medicaid Services. Adjustments for inflation were then calculated using the United States Bureau of Labor Statistics - The Consumer Price Index inflation calculator.[19]

\section{RESULTS}

The incidence of laminectomy for the excision of herniated intervertebral disc decreased dramatically from a starting point of 266,152 cases in $1993 \mathrm{SE}=11,399 ; 95 \% \mathrm{CI}=22,342$. In 2007, there were only 123,398 cases reported $\mathrm{SE}=6,346 ; 95 \% \mathrm{CI}=12,438 ; \mathrm{z}$ statistic $=10.94, \mathrm{SE}=13,046.41, \mathrm{P}($ two tailed) $=0.000$. [ Figure 1] The average length of stay in 1993 was 4 days [SE 0.1; CI $=0.17$ ]. In 2007, it decreased to just 2 days $[\mathrm{SE}=0.1 ; \mathrm{CI}=0.17]$; $\mathrm{z}$ statistic $=14.14, \mathrm{SE}=0.14, P($ two tailed $)=0.000$. Both comparisons were significant at $P<0.001$.

The charges associated with a laminectomy for the excision of herniated intervertebral disc in 1993 averaged 10,308 USD [SE=326; CI 550.94]. This value rose in 2007 to 24,639 USD [SE = 879; CI = 1485.51]; $\mathrm{z}$ statistic $=15.29, \mathrm{SE}=937.51, P($ two tailed $)=0.000$. This comparison was significant at $P<$ 0.001. To adjust for inflation, the 1993 charges were manipulated to reflect buying power in the year 2007. This brought the average charge of the procedure in 1993 to $14,790.87$ USD [SE= 467.78; CI $=916.85$ ], $\mathrm{z}$ statistic 9.90, $\mathrm{SE}=995.72, P($ two tailed $)=0.000$. The differences in inflation adjusted comparison remained significant at $\mathrm{P}<0.001$.

The incidence of spinal fusion procedures (HCUP Clinical Classifications Software category 158) increased dramatically from a starting point of 60,973 cases in 1993 [SE $=5,108 ; 95 \% \mathrm{CI}=10,011.68]$. to $350,754$ cases reported in $2007 \mathrm{SE}=18,068 ; 95 \% \mathrm{CI}=35,413.28]$; $\mathrm{z}$ statistic $=15.43, \mathrm{SE}=18,776.16, \mathrm{P}$ (two tailed $)=0.000$. [Figure 2] The average length of stay in 1993 was 7.7 days SE 0.2; CI $=0.39$ ]. In 2007, it decreased to just 3.9 days $[\mathrm{SE}=0.1 ; \mathrm{CI}=0.17]$; $\mathrm{z}$ statistic $=16.99, \mathrm{SE}=0.22, \mathrm{P}$ (two tailed) $=$ 0.000 . Both comparisons were significant at $\mathrm{P}<0.001$.

The charges associated with a spinal fusion in 1993 averaged 24,045 USD [SE=1,406; CI 2376.14]. This value rose in 2007 to 74,672 USD [SE = 2,069; CI = 3496.61]; z statistic $=20.24, \mathrm{SE}=2,501.52, P$ (two tailed $)=0.000$. This comparison was significant at $P<0.001$. To adjust for inflation, the 1993 charges were manipulated to reflect buying power in the year 2007. This brought the average charge of the procedure to 34,502 USD SE=2017.46; $\mathrm{CI}=3,954.22$, $\mathrm{z}$ statistic $13.90, \mathrm{SE}=2,889.79, P$ (two tailed) $=$ 0.000 . The differences in inflation adjusted comparison remained significant at $P<0.001$.

\section{DISCUSSION}

We studied a population of patients undergoing inpatient, non-instrumented surgical treatment of herniated intervertebral discs using a nationally representative hospital discharge database. The results of our analysis showed that the incidence laminectomy (performed as a principal procedure) has dramatically decreased during the study period from 1993 to 2007.

Surgery has long been viewed as the definitive treatment for symptomatic intervertebral disc herniation since the condition as first described by Mixter and Barr as a surgical disease.[16] Fueled by dramatic early reports regarding the success of operative therapy, such as the "complete and permanent resolution of leg pain" following surgery in 33 of 34 cases of herniated lumbar discs as discussed in this paper,[15] rates of lumbar discectomy rose dramatically in the US.[17] However, over the past two decades, several studies have called into question the universal benefit of operative intervention for cases of intervertebral disc herniation with mild to moderate symptom profiles. $[\underline{5}, \underline{6}, \underline{12}-\underline{14}, \underline{18}, \underline{20}]$ Since $10 \%$ of Americans experience 
chronic low back pain and lumbosacral disc herniation is thought to be the primary cause of low back pain in nearly $30 \%$ of persons with chronic low back pain, establishing the efficacy of costly surgical interventions for intervertebral disc herniation has significant implications both for optimal patient management and healthcare policy.[10,21]

Recent comparisons of conservative management strategies to operative interventions for intervertebral disc herniation have helped to elucidate the natural history for mild to moderate disc herniations. The degree to which this has affected the rate of laminectomy for intervertebral disc is debatable. In the cervical spine, two prospective trials followed 48 and 68 patients with mild to moderate cervical spondylotic myelopathy for 2 and 3 years, respectively. After randomization to either conservative therapy or surgery, it was found that no significant differences between the two groups existed in terms of objective measures of functional status and self-perceived sense of clinical status.[12, $\underline{13}]$

In addition to cervical disc herniation, studies have also been performed that assess the utility of operative intervention in the case of thoracic disc herniation.[] However, no study to date has directly prospectively assessed the efficacy of intervention in symptomatic patients when compared to non-operative treatment. By far, the greatest number of studies addressing the utility of operative intervention has been directed at the population of symptomatic individuals with lumbar interveterbral disc herniations. The largest study of surgical intervention for lumbar disc herniation was the SPORT trial which enrolled 501 and 743 patients with symptomatic, imaging-confirmed lumbar intervertebral disc herniation into prospective randomized and prospective observational studies, respectively.[20] In the intent to treat analysis of the prospective randomized controlled trial, only the sciatica bothersomeness index (a secondary outcome measure) was improved in the surgery group for the duration of the 4 year follow-up period. Furthermore, as the authors note, the combined as-treated analysis is not protected from cofounding variables; therefore, it is difficult to interpret the true benefit of surgical therapy, particularly with significant cross-over seen in the trial execution. Another large randomized controlled trial involving symptomatic lumbar disc herniation demonstrated that these patients receive more rapid symptom relief by undergoing surgery, but 1 and 2 years post-operatively their symptoms and quality of life are equivalent to those patients who received 2 years of conservative care.[18] Whereas absolute clinical evidence is lacking regarding many aspects of herniated intervertebral discs, it is the duty of the clinician to evaluate the available data and implement clinical plans that reflect a thoughtful analysis.

While initial reflection of the current literature generally suggests an expanding body of evidence in support for the effectiveness of conservative management in alleviating the symptoms of many herniated intervertebral discs, the overall incidence of procedures performed for the same has markedly increased. How then, does this relate to a decreasing rate of inpatient laminectomy for herniated intervertebral discs? We suspect the cause to be the rising rates of ambulatory setting surgery and spinal fusion to be implicated in generating the decreased incidence of inpatient laminectomy. For example, the proportions of discectomies performed on outpatients rose from 4\% in 1994 to $26 \%$ in 2000.[11] Outpatient discectomies have been reported to be effective and it is assumed that by forgoing inpatient hospitalization, costs are lowered.[2-4] No rigorous cost analysis or equivalence trial for outpatient discectomy has yet been performed. In a similar time frame from 1993?2003, a previously published analysis has indicated that overall utilization increased during the time period for cervical, thoracolumbar, and lumbar fusions by 89 , 31 , and $134 \%$, respectively.[욜] The trends described in this manuscript suggest that incidence of spinal fusion procedures continues to increase. In looking at the 2007 NIS database rank list of all patients in all hospitals, spinal fusion has risen to the $35^{\text {th }}$ most common inpatient procedure.

Limitations of this analysis reflect inherent deficiencies of a nationwide, code-based database. The database does not account for timing of the procedure, severity of disc herniation, or the identification of unique situations such as "traumatic disc." There is no record of the degree of neurological impairment (if any) or the number or location of intervertebral levels involved. Re-operation rate is not accounted for in 
the database. Coding practices themselves may not reflect a completely accurate assessment of patient care rendered.

\section{CONCLUSION}

There is a growing body of evidence which suggests that surgical excision of herniated intervertebral disc is beneficial in a select group of patients. For many patients, non-operative management has proven an equivalent treatment option. Estimates from the Nationwide Inpatient Sample indicate that surgical procedures coded most specific to the inpatient surgical (non-instrumented) treatment of herniated intervertebral disc disease have significantly decreased. Increases in ambulatory surgery and spinal fusion have been documented and are likely implicated in the decreasing incidence of inpatient laminectomy for herniated intervertebral disc.

\section{Footnotes}

Available FREE in open access from: http://www.surgicalneurologyint.com/text.asp?2011/2/1/7/76144

\section{REFERENCES}

1. HCUP Nationwide Inpatient Sample (NIS) Healthcare Cost and Utilization Project (HCUP) [Internet] [last cited on 1992]. Available from: http://www.hcup-us.ahrq.gov/nisoverview.jsp .

2. Asch HL, Lewis PJ, Moreland DB, Egnatchik JG, Yu YJ, Clabeaux DE, et al. Prospective multiple outcomes study of outpatient lumbar microdiscectomy: Should 75 to $80 \%$ success rates be the norm? J Neurosurg. 2002;96:34-44. [PubMed: 11795712]

3. Best NM, Sasso RC. Outpatient lumbar spine decompression in 233 patients 65 years of age or older. Spine. 2007;32:1135-9. [PubMed: 17471098]

4. Best NM, Sasso RC. Success and safety in outpatient microlumbar discectomy. J Spinal Disord Tech. 2006;19:334-7. [PubMed: 16826004]

5. Brown CW, Deffer PA, Akmakjian J, Donaldson DH, Brugman JL. The natural history of thoracic disc herniation. Spine. 1992;17:S97-102. [PubMed: 1631725]

6. Buttermann GR. Treatment of lumbar disc herniation: Epidural steroid injection compared with discectomy.A prospective, randomized study. J Bone Joint Surg Am. 2004;86-A:670-9.

[PubMed: 15069129]

7. Chen TC. Surgical outcome for thoracic disc surgery in the postlaminectomy era. Neurosurg Focus. 2000;9:e12. [PubMed: 16833242]

8. Cowan JA, Dimick JB, Wainess R, Upchurch GR, Chandler WF, La Marca F. Changes in the utilization of spinal fusion in the United States. Neurosurgery. 2006;59:15-20. [PubMed: 16823295]

9. Deyo RA, Gray DT, Kreuter W, Mirza S, Martin BI. United States trends in lumbar fusion surgery for degenerative conditions. Spine. 2005;30:1441-5. [PubMed: 15959375]

10. Freburger JK, Holmes GM, Agans RP, Jackman AM, Darter JD, Wallace AS, et al. The rising prevalence of chronic low back pain. Arch Intern Med. 2009;169:251-8. [PMCID: PMC4339077] [PubMed: 19204216]

11. Gray DT, Deyo RA, Kreuter W, Mirza SK, Heagerty PJ, Comstock BA, et al. Population-based trends in volumes and rates of ambulatory lumbar spine surgery. Spine. 2006;31:1957-63. [PubMed: 16924213]

12. Kadaňka Z, Bednarřik J, Vohnáňka S, Vlach O, Stejskal L, Chaloupka R, et al. Conservative treatment versus surgery in spondylotic cervical myelopathy: A prospective randomised study. Eur Spine J. 
13. Kadanka Z, Mares M, Bednaník J, Smrcka V, Krbec M, Stejskal L, et al. Approaches to spondylotic cervical myelopathy: Conservative versus surgical results in a 3-year follow-up study. Spine.

2002;27:2205-10. [PubMed: 12394893]

14. Matsumoto M, Chiba K, Ishikawa M, Maruiwa H, Fujimura Y, Toyama Y. Relationships between outcomes of conservative treatment and magnetic resonance imaging findings in patients with mild cervical myelopathy caused by soft disc herniations. Spine. 2001;26:1592-8. [PubMed: 11462093]

15. Mixter W, Ayer J. Herniation or rupture of the intervertebral disc into the spinal canal: Report of thirtyfour cases. N Engl J Med. 1935;213:385-93.

16. Mixter W, Barr J. Rupture of the intervertebral disc with involvement of the spinal cord. N Engl J Med. $1934 ; 211: 210-5$.

17. Parisien RC, Ball PA. William Jason Mixter (1880-1958).Ushering in the "dynasty of the disc" Spine. 1998;23:2363-6. [PubMed: 9820919]

18. Peul WC, van den Hout WB, Brand R, Thomeer RT, Koes BW. Prolonged conservative care versus early surgery in patients with sciatica caused by lumbar disc herniation: Two year results of a randomised controlled trial. BMJ. 2008;336:1355-8. [PMCID: PMC2427077] [PubMed: 18502911]

19. United States Bureau of Labor Satistics. The Consumer Price Index inflation calculator. [last cited in 2010 Apr 4]. Available from: http://www.bls.gov/data/inflation calculator.htm .

20. Weinstein JN, Lurie JD, Tosteson TD, Skinner JS, Hanscom B, Tosteson AN, et al. Surgical vs nonoperative treatment for lumbar disk herniation: The Spine Patient Outcomes Research Trial (SPORT) observational cohort. JAMA. 2006;296:2451-9. [PMCID: PMC2562254] [PubMed: 17119141]

21. Zhang Y, Guo T, Guo X, Wu S. Clinical diagnosis for discogenic low back pain. Int J Biol Sci. 2009;5:647-58. [PMCID: PMC2764347] [PubMed: 19847321]

\section{Figures and Tables}

Figure 1

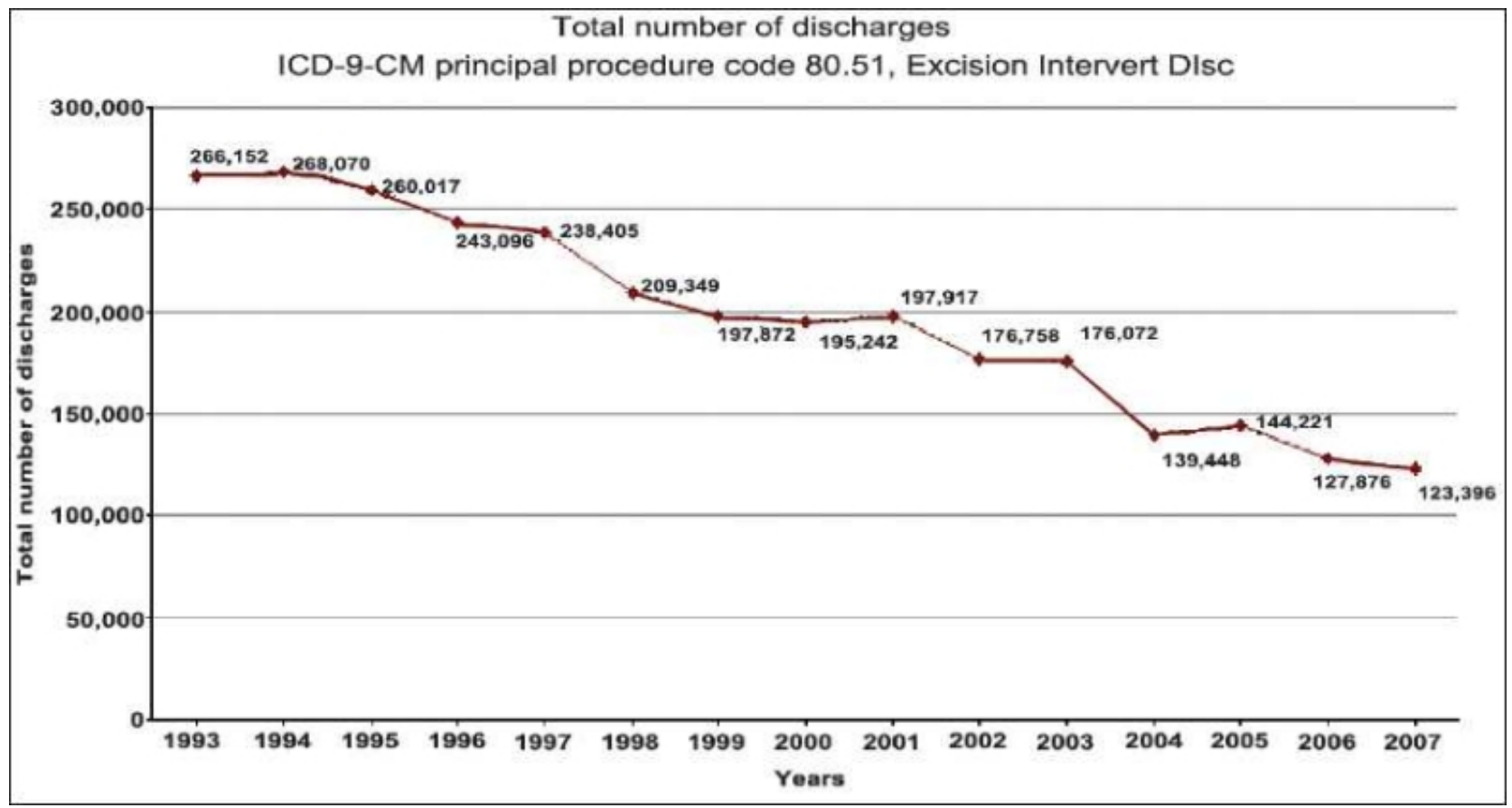




\section{Figure 2}

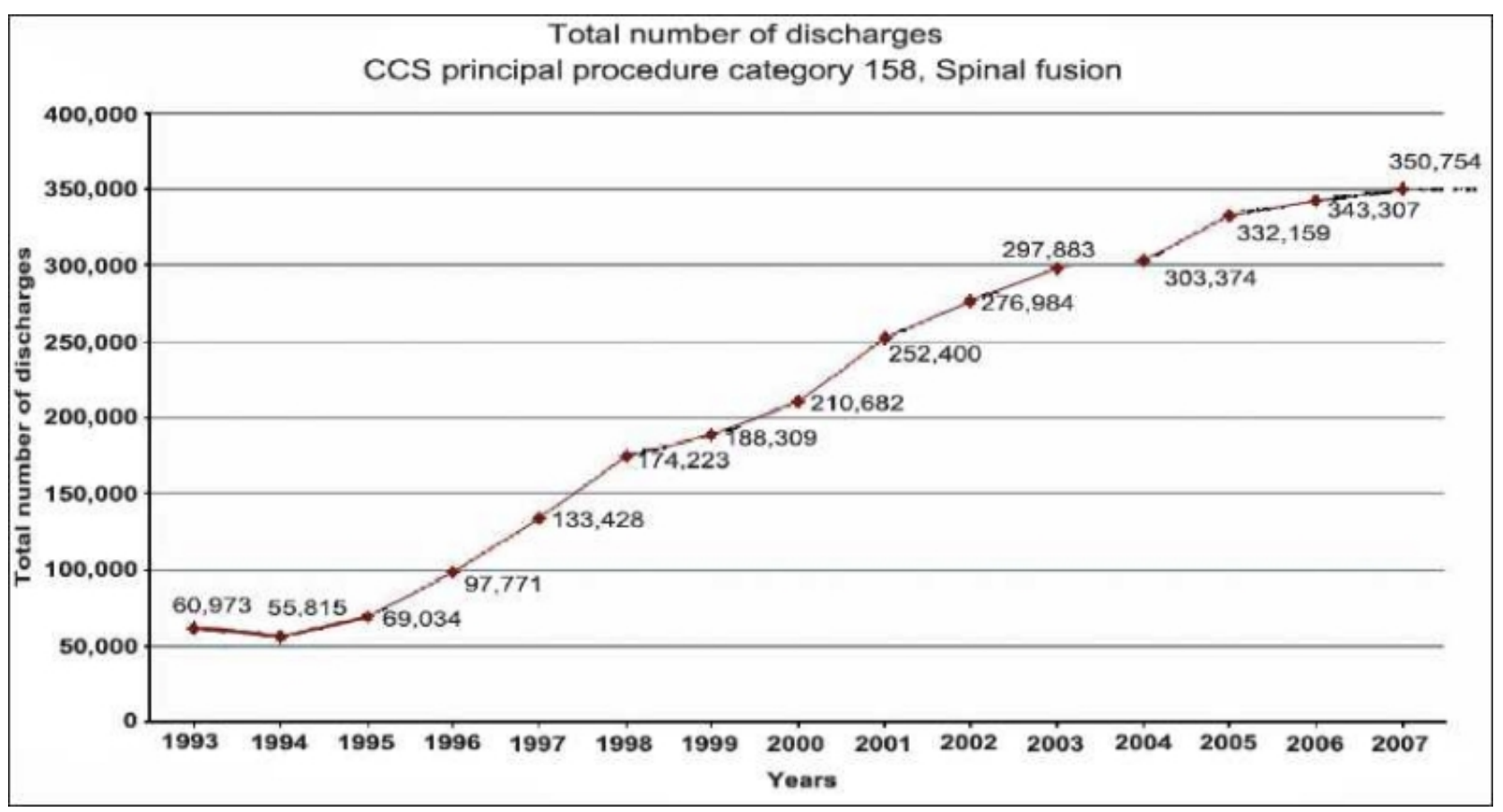

Time trends in incidence rates for spinal fusion procedures (1993-2007).

Articles from Surgical Neurology International are provided here courtesy of Medknow Publications 